\title{
Consequence Theory of Truth. Reflections on Certainty and Conflict
}

\author{
BERNHARD POERKSEN, HAMBURG
}

\section{For Josef Mitterer}

Summary: The constructivist criticism of truth can be reconstructed as a theory of truth that will be called consequence theory of truth; this theory of truth oscillates between epistemological understanding and ethicalmoral concern. It does not deal with the conventional question of traditional theories of truth that explain the concept of truth and describe the realisation of truth (by correspondence, experience of evidence, internal consistency of statements within a system of statements etc.). The focus of a constructivist criticism of truth that may be conceived of as a theory of truth are the potential consequences of the belief in truth, which can be assigned to a logical-semantical level, an individual-cognitive level, and the domain of relations. The strict belief in (absolute) truth can be seen, as certain constructivist authors imply, as a source of interpersonal conflict.

\section{Conditions of dominance}

The variability of the possible views of the connection between epistemology and ethics becomes clear when one compares the comments on the concept of truth offered by some of the protagonists of constructivism. "I think", writes Humberto R. Maturana, amongst others, "there is a fundamental alienation to which we are prone: the search for truth, the search for the absolute, the desire for ultimate stability through the denial of change; the desire that the world should be in the manner that satisfies our desires, and as such and with respect to that, stable. [...] But how do we act? We invent systems of consensual stability that we claim are absolute truths that must be protected against change because we deem their value to be universal. In their name we deny the individuality of others that live in a different consensus and, without allowing them to disagree, we submerge them in a systematic social abuse that we expect they should accept as legitimate. This is our most frequent alienation: our blindness about the world of relative truths that we create with others, and in which man is the absolute reference, and our immersion in an ideology that justifies this 
blindness." (Maturana 1985, 29; author's original English text, unpublished.) Some speak of truth terrorism, some of "reality terror" (Weischenberg, quoted from Neuberger 1996, 228). Paul Watzlawick writes that there is, "hardly a more murderous, more despotic idea [...] than the delusion of a 'real' reality" (quoted from Neuberger, ibid.). The claim to absolute truth, Siegfried J. Schmidt states succinctly, "inevitably leads to oppression" (quoted from Neuberger, 228f). Thus, all these and similar pronouncements, we may conclude, practise a form of criticism of an emphatic notion of truth that connects epistemology and ethical-moral concern. This kind of criticism may be taken to be a proper constructivist theory of truth ${ }^{1}$ and will from now on be called consequence theory of truth. ${ }^{2}$

To elucidate this thesis, some general remarks on the philosophical treatment of the question of truth will be helpful; only this necessary detour and such an unavoidable excursion into the domain of philosophy can yield the relevant criteria of description that will then enable us to explicate the peculiarities of a consequence theory of truth. What can be stated right away, in any case, is that the theories of truth discussed by philosophers

\footnotetext{
${ }^{1}$ Constructivism is an interdisciplinary school of thought firmly rooted in science, especially biology, and of particular relevance to the understanding of media-generated realities. The champions of this school of thought emphatically reject representationist theories and realist conceptions of perception and share the conviction that objective knowledge is essentially unobtainable. They do not deny the existence of an external world; they negate, however, its unconditional cognitive accessibility and, therefore, insist on a critical examination of how concepts of reality are manufactured. All the varieties of constructivist theorising, whether centred in neurobiology, psychology, the sociology of knowledge, or communication science, additionally share the fundamental conviction that knowledge does not consist in a direct correspondence with an external reality (correspondence theory of truth) but exclusively and inevitably in the constructions of an observer, a knowing subject. However, these constructions are neither arbitrary nor capricious, on the contrary, they are massively dependent on all sorts of preconditions: construction is not an individual act of creation, nor a process under conscious control, but something multiply conditioned by nature and culture, history, language, and in particular also by the media that operate as central instances of socialisation in modern societies. The reader should be aware that I use the term constructivism in order to refer to the work of Humberto Maturana, Heinz von Foerster, Ernst von Glasersfeld, Siegfried J. Schmidt, Francisco Varela and Paul Watzlawick. They have also been labelled as radical constructivists. Other constructivist schools of thought are not meant and not mentioned.

${ }^{2}$ The concept of theory used in this context - in contradistinction to the more rigorously developed philosophical theories of truth - is obviously a diffuse one and means something like conception, understanding, view. It is not a terminus technicus. See also Gloy 2004, 5.
} 
are primarily the subject of epistemological, not ethical, reflection. With reference to a famous distinction introduced by Immanuel Kant, they deal with the key question of what human beings can know, and not the question of what they should do, how they should act (which would accordingly belong to the domain of ethics).

This localisation of the question of truth in the domain of epistemology is made additionally clear by the fact that all the different conceptions of truth, and ultimately also all the different types of truth theory, may be sorted according to the guiding difference subject/object, and that the kind of chosen relation between subject and object, i.e. between observer and observed, makes it possible to observe the differentiation of all the particular theories of truth. Depending on the peculiar relation established between subject and object one may, in a first step, distinguish between three fundamentally different possibilities of characterising this relation. The first basic type results from "preferring the objective side and neglecting the subjective. The domain of the objects is given absolute or at least relative dominance. It is assumed that the objects in their being and suchness, in their determinants and their relationships with other objects, exist in themselves, quite independently of whether there is a cognising being apprehending them or not. The things possess their own peculiar being in themselves as well as their own specific properties to which the human subjects must subordinate themselves in an act of apprehension. [...] In a process of acquiring knowledge, human subjects must subordinate themselves to what is given, must appropriate what is available. [...] This is the position of common sense, of the natural, everyday, pre-scientific way of handling things. Elevated to a philosophical position, it represents realism from its most naïve to its most sublime forms." (Gloy 2004, 68) According to the systematisation introduced here, the other epistemological extreme is marked by idealism; here the hierarchisation of subject and object is inverted, as it were; the world of objects becomes dependent on the cognitive grasp of the knowing subject. The third type of knowledge emerges "when the two relata within the cognitive relation, the knower and what is to be known, are treated as equivalent and as of equal status, so that a correspondence is achieved between the world of the subjects and the world of the objects." (Gloy 2004, 69) 


\section{Philosophical theories of truth}

It is this variable evaluation and hierarchisation of subject and object, which leads to three different concepts of truth and types of truth theory:

- The assumption of ontic truth (also: objective truth, factual truth etc.) which is advocated in the frame work of a so-called theory of ontic truth, assigns unconditional primacy to the world of objects; the subject's task here is to open up, to become permeable, in order to receive "what there is such as it is in itself" (Gloy 2004, 78), uncluttered and undistorted. The experience of truth, possibly supported by existentially dramatic feeling, consists in a kind of revelation, a becoming-apparent of the world of objects in its archetypal gestalt, and thus clearly exhibits mystical-metaphysical colouring: within such a conception, the idea of Being possesses qualities otherwise only granted to the Divine, as Karen Gloy has shown with reference to Martin Heidegger. (Gloy 2004, 78f.)

- The position maximally removed from this understanding of truth relocates the apprehension of truth to the rational sphere of the subject (logical truth) and transforms the experience of suchness into a perception of coherence, freedom from contradiction, or perhaps consensus. The result are subject-immanent theories of truth; they have been given different forms and thus exist in diverse variants. The coherence theory of truth in its pure form restricts itself to "the subjective domain of knowledge" and relies on "the ability of a statement to be integrated into a system of statements, to be compatible with the other statements." (Gloy 2004, 168) Here truth means: freedom from contradiction, consistent integration. The consensus theory, or discourse theory, of truth as proposed by Jürgen Habermas, for instance, also rejects any kind of reference beyond discourse, insists on subject-immanent argumentation; truth is here conceived of as the discursive satisfaction of claims to validity and is founded upon consensus manufactured in an ideal speech situation.

- The concept of truth mediating between the object side and the subject side has recourse to the famous formula coined by Thomas Aquinas (adaequatio intellectus et rei) and aims to understand truth as correspondence between subject and object, as a relation of correspondence between the knowing subject and the known object. The actual exposition of the diverse correspondence theories of truth depends heavily on how the kind of correspondence is specified, how the accommodation of subject and object 
is worked out in detail. ${ }^{3}$ Is there a mapping relation, a mirroring of what is apprehended in the knowing mind? If so, this correspondence theory could be interpreted as a kind of reflection theory. Is there a causal nexus, a relation of cause and effect? Then the knowledge reached by the subject would be the result and consequence of the impression emanating from the object world which is received by the subject, in fact imposes itself on the subject in its archetypal formation. In any case, each one of the variants of a correspondence theory must face up to the problem how correspondence is to be understood and how all those essentially heterogeneous entities (subject, mind, cognition) and domains (world of objects, things, phenomena) are or can at all be - integrated with each other in such a way as to achieve the desired ultimate state of assimilation and total structural isomorphism.

\section{Criticism of truth as theory of truth}

If the observer schema that underlies the discussion of traditional theories of truth is also used for the reconstruction of the constructivist theory of truth, then striking differences become apparent. The systematic locus of the consequence theory of truth is not only epistemology but also ethics, i.e. the concern for the other that may be oneself. This means that there is a characteristic uncertainty regarding its disciplinary placement, which may be summarised in the following formula: consequence theory can be justified epistemologically, its ultimate motivation, however, is an ethicalmoral one. In the context of an epistemological discourse, one deals - quite traditionally - with the relationship between subject and object, observer and observed. Ontic and correspondence-theoretical concepts of truth are rejected, subject-immanent ones favoured.

Arguing, however, from an ethical-moral perspective, makes a different relational structure emerge: it is the relation between subject and subject, between various observers, possibly including ourselves as observers reflecting the cognitive costs and the consequences of our very own ideas of truth. Furthermore - and again in contrast to traditional theories of truth - , the central problem for consequence theorists is not primarily the definition of the concept of truth or the specification of criteria of truth (evidence, consensus, utility etc.), i.e. the explication of the realisation of truth. Nor is it a primary goal to pass judgment on the truth or falsity of statements and to set up the corresponding criteria of differentiation, but much rather to ponder and bring to awareness the possible effects of the distinction

\footnotetext{
${ }^{3}$ On the variants of correspondence theory see Gloy 2004, $93 \mathrm{ff}$.
} 
true/false - therefore the chosen label consequence theory of truth. It asserts nothing about the essence of truth like traditional theories of truth, says nothing about its realisation, but deals with the consequences that result from the conviction to be in the possession of unquestionable truth. One can distinguish, at least as ideal types, logical-semantical consequences, individual-cognitive consequences and consequences for the domain of relations.

\subsection{The logical-semantical level}

Heinz von Foerster has graphically highlighted the logical-semantical consequence of the use of the concept of truth with his aphorism that truth is the invention of a liar. ${ }^{4}$ It formulates succinctly that truth and lie depend on each other, refer to each other, and form a logical-semantical system of reference that remains in force even when the possibility of any access to truth is rejected. The meaningfulness of the concept is affirmed, in any case, and a conceptual master currency is introduced that directs one's orientation - however clear its restrictions. Tied to such a logical-semantical perspective, it is impossible to free oneself from concepts considered problematical by means of their negation because their very negation still accentuates their relevance. One can only get rid of them by simply not mentioning them, thus pushing them back into a sphere of non-existence, depriving them of their pedestal and fundament as the transcendental condition of their thematisation. They will then drop back into an amorphous and shapeless field that one cannot appropriate cognitively because it is unmarked by distinctions and designations. In this case, the fundamental statement by George Spencer-Brown, the first commandment regarding the creation of a concept of observation based on a logic of distinctions, would have to be changed. The requirement would no longer be: "Draw a distinction!" but: "Drop a distinction!" One puts distinctions, perhaps even systems of distinctions, behind oneself by flatly refusing to discuss, negate, affirm, defend or criticise them. Distinctions are deleted from the discourse because they no longer occur, because they are no longer needed. ${ }^{5}$

\footnotetext{
${ }^{4}$ See Foerster/Poerksen 2002, especially 30f., in addition, with reference to the distinction sickness/health, $76 \mathrm{ff}$.

${ }^{5}$ This operator is discussed in the conversation with Foerster in: Poerksen 2004, $20 \mathrm{ff}$.
} 


\subsection{The individual-cognitive level}

It is one of the basic tenets of constructivism that there is an almost limitless plurality of reality designs, of concept arrangements, of ways to punctuate an event, to construct causality and to create meaning. By contrast, the defenders of a single truth reduce the multitude of potential interpretations of reality to one single certainty, to one ultimate determination of what is or should be considered absolutely right. One possible individualcognitive consequence of such certainty about truth is, therefore, that it makes alternatives of thinking, feeling, and acting invisible, as it were, and that it may grow into the compulsion to say the same thing on all occasions, or to have to offer more or less similar answers all the time, to say he least. Although one may thus be protected from the endless circling in the labyrinth of undecidable questions, such certainty about truth may make the sympathetic re-enactment of other, contrary, views difficult, perhaps even impossible. (See Morin 2001, 82) It may, moreover, eliminate the need for radical scepticism and may, according to Humberto R. Maturana, as long as it is not a question of securities required by the situation in hand, "make all further reflection seem a waste of time: We believe we already know in advance the only possible result of any renewed reflection effort. What, in fact, do we really mean when we say we are absolutely sure of something? We say: There is no point in entertaining doubts; our beliefs are so overwhelming that it must appear completely absurd to think about the conditions of their origins." (Maturana/Poerksen 2004, 45)

\subsection{The level of relations}

The majority of the writings from constructivist circles, which deal with the problem of the presumption of truth, however, do not refer to the logical-semantical or the individual-cognitive level. They are devoted to the sphere of human relations, the sphere of interaction. The basic point of reference is the relationship between autonomous individuals, a relationship constituting, as it were, the prototypical pattern of a potentially ethical or unethical relation. Two possible variants of consequence may be distinguished on this level: on the one hand, there is the negation of the other as well as of other views, which is inherent in the belief in absolute truth. Numerous protagonists of constructivism - recall only Heinz von Foerster, Niklas Luhmann, Humberto R. Maturana, Josef Mitterer, Siegfried J. Schmidt, Paul Watzlawick and Siegfried Weischenberg - have argued in 
this way, and have never failed to insist on the need for careful gradation. ${ }^{6}$ Quite conceivable are concepts of truth that - although contradicting most of the definitions of truth - do not, or are not intended to, claim validity for anyone else but their advocates. They are excepted from the criticism, which targets only the generalisation of individual assumptions by means of dogmatically justified claims to truth. Truth in the sense of a concern based on consequence theory entails a static-dogmatic view of the concept that negates other views and considers the respect for these views to be wrong and counterproductive and therefore dispensable, in the service of a good cause. At issue is the argumentative or pseudo-argumentative appeal to the truth concept and related ideas, which are, for the purpose in hand, considered equivalent, like true, real, definite, certain, with ultimate certainty, objective, reality, the absolute. They are functionally equivalent; they all serve comparable purposes, e.g. making something plausible, convincing and persuading people, but also discrediting and defaming people in conflict discourses. ${ }^{7}$

In one of Humberto R. Maturana's exemplary formulations: "If we do not accept our interlocutor totally, or we want to assert our position, or we are certain that we are right, or we want to force the other to perform certain actions, we explicitly or implicitly claim that what we say is valid because it is objective (that is, founded on an objective reality), that we know how things really are, that our argument is rational, and that the other is objectively wrong and cannot honestly ignore it." (Maturana 1988, 46) Some of the possible consequences of this first consequence-theoretical reflection in the domain of relations would be: intolerance and a dogmatically fought quarrel, a lack of respect for other views, attempts at conversion, the menace of homogenising reality designs, demands for subordination, discrimination and defamation. The second variant of possible consequences deals with the legitimation of violence; in such justifications of aggressivity the use of power and, in the extreme case, even of physical force is endorsed with the argument that only in this way - thus runs the figure of thought elaborated by consequence theorists, and which is subjected to criticism - truth could regain its rightful place, and detrimental untruth be eliminated. (See Mitterer 2001, 64) Paul Watzlawick has de-

\footnotetext{
${ }^{6}$ Reflections on the links between the belief in truth and the negation of the other may be found in: Foerster (Foerster/Poerksen 2002, 30ff.); Luhmann 1994, 11; Maturana 1998, 226ff.; Mitterer 2001, 64ff.; Schmidt 1991, 47f.; Watzlawick 1994, 204ff. and Weischenberg 1993, 129.

${ }^{7}$ On the concept of conflict discourse see Mitterer 2001, 77.
} 
scribed in precise words this gradual transition from the initial desire to convert the other to the wish to subjugate them, ending finally in an act of purposeful aggression: "The idea to be in the possession of ultimate truth will at first lead to a messianic attitude clinging to the conviction that the truth will prevail qua truth in any case. At this point, the protagonist of an ideology may still believe in the possibility of enlightening and perhaps convincing the heretic. As the world, however, soon proves to be hardhearted, unwilling or incapable to open itself to the truth, the inevitable next step is what Hermann Lübbe has called the ideological selfempowerment for the use of force. The world must have its eyes opened for its own best interests." (Watzlawick 1994, 204f; author's emphasis) The appeal to an ultimate, dogmatically conceived truth is, therefore, generally seen to be a destructive incentive in the field of human relations. Truth in this understanding is not only a means to deform these relations and to ruin the climate of communication but may also lend an air of apparent necessity to violent disputes.

\section{Between epistemology and ethics}

The essential features of a consequence theory of truth have now been described, of a theory that oscillates between epistemology and ethics in a characteristic way, that analyses conflicts and reconstructs strategies of legitimating the privileged establishment and enforcement of views decreed to be true. It may, at this point, be a mere matter of speculation but it does indeed seem more than accidental that the very founders of constructivism developed reflections of this sort; all of them had to suffer under dictators, were confronted with dogmatically founded realities. Heinz von Foerster, working in Berlin during the period of National Socialism without the obligatory "Ariernachweis" (proof of "Aryan" descent), had to evade the inevitable checks by a careful tactic of procrastination. Ernst von Glasersfeld left Vienna after the National Socialists had seized power; Paul Watzlawick has repeatedly deplored how deeply shocked he felt by the NS-regime. Francisco Varela - after the death of Salvador Allende and the military coup of the putschist Pinochet - fled to Costa Rica. Humberto R. Maturana stayed in Chile - despite repeated threats - in order to experience, "what it means to live under a dictator" and in order to observe, "how people gradually go blind ", even though they may be well aware "of the dangers of a blindness produced by ideology". He recollects: "I also asked myself whether I might be able to observe in such a dictatorial system how 
people gradually go blind, and what the causes of such perceptual deprivation were. Can one, if one has been duly forewarned and is aware of the dangers of ideologically produced blindness, prevent it from developing and retain one's capabilities of vision and perception?" (Maturana/Poerksen 2004, 168)

An instructive picture such as this one, illuminating the background of individual lives as well as the history of the practice of science, can of course contribute nothing to the plausibility of the criticism of truth and the criticism of truth theories presented here; it may, however, speak for examining more closely the links between theory development and individual biography. It also shows that the justification of the arguments introduced here can only be achieved in a wider context. The polemical overstatement, too, has no proper justifying quality, although it may be an acceptable corrective. It certainly is, as has become clear, a reaction against mental rigidity, against dogmatically defended reality designs, and against the form of the authoritarian-dictatorial presumption of truth which declares the use of force in conflicts - explicitly or implicitly - a legitimate means of its practical implementation.

\section{REFERENCES}

Foerster, H. von / Poerksen, B. 2002 Understanding Systems. Conversations on Epistemology and Ethics, Heidelberg/New York: Carl-Auer-Systeme Verlag/Kluwer Academic Publication/Plenum Publishers.

Gloy, K. 2004 Wahrheitstheorien. Eine Einführung, Tübingen/Basel: A.Francke.

Luhmann, N. 1994 „Der 'Radikale Konstruktivismus` als Theorie der Massenmedien? Bemerkungen zu einer irreführenden Debatte“, Comunicatio Socialis, 27 (1), 7-12.

Maturana, H.R. 1985 Erkennen. Die Organisation und Verkörperung von Wirklichkeit. Ausgewählte Arbeiten zur biologischen Epistemologie, 2., durchges. Aufl. Braunschweig/Wiesbaden: Vieweg.

- 1988 "Reality: the search for objectivity; or the quest for a compelling argument", The Irish Journal of Psychology, 9 (1), 25-82.

Maturana, H.R. / Poerksen, B. 2004 From Being to Doing. The Origins of the Biology of Cognition, Heidelberg: Carl Auer.

Mitterer, J. 2001 Die Flucht aus der Beliebigkeit, Frankfurt am Main: Fischer.

Morin, E. 2001 Seven Complex Lessons in Education for the Future, Paris: UNESCO Publishing.

Neuberger, C. 1996 Journalismus als Problembearbeitung. Objektivität und Relevanz in der öffentlichen Kommunikation, Konstanz: UVK Medien. 
Poerksen, B. 2004 The Certainty of Uncertainty - Dialogues Introducing Constructivism, Exeter: Imprint Academic.

Schmidt, S.J. 1991 „Der Radikale Konstruktivismus: Ein neues Paradigma im interdisziplinären Diskurs“, in J. Siegfried und J. Schmidt (Hgg.), Der Diskurs des Radikalen Konstruktivismus, 4. Aufl, Frankfurt am Main: Suhrkamp, 11-88.

Watzlawick, P. 1994 „Bausteine ideologischer 'Wirklichkeiten““ in P. Watzlawick (Hrsg.), Die erfundenene Wirklichkeit. Wie wissen wir, was wir zu wissen glauben? Beiträge zum Konstruktivismus, 8.Aufl., München/Zürich: Piper, 192-228.

Weischenberg, S. 1993 „Die Medien und die Köpfe. Perspektiven und Probleme konstruktivistischer Journalismusforschung“, in G. Bentele / M. Rühl (Hgg.), Theorien öffentlicher Kommunikation. Problemfelder, Positionen, Perspektiven, München: Ölschläger, 126-136. 
